\title{
Direct effects of oestradiol-17ß and prostaglandin E-2 in protecting pig corpora lutea from a luteolytic dose of prostaglandin $\mathbf{F}-2 \alpha$
}

\author{
S. P. Ford* and L. K. Christenson \\ Department of Animal Science, Iowa State University, Ames, IA 50011, USA
}

\begin{abstract}
Summary. Implants containing vehicle or oestradiol-17 $\beta(10 \mathrm{mg})$ were placed into pairs of corpora lutea (CL) with and without prostaglandin F- $2 \alpha(\mathrm{PGF}-2 \alpha)(100 \mu \mathrm{g})$ on Day 11 and CL were collected on Day 19, in cyclic gilts (Exp. 1). The results demonstrated that CL implanted with PGF-2 $\alpha$ with or without oestradiol-17 $\beta$ had a markedly lower $(P<0.01)$ weight $(\mathrm{mg})$ and progesterone concentration $(\mathrm{ng} / \mathrm{mg})$ than $\mathrm{CL}$ with vehicleor oestradiol-17 $\beta$-implanted or unimplanted $C L$, which were similar (149 and $7 \cdot 2$ vs. 304 and 49.6, respectively). In Exp. 2, CL implanted with vehicle, oestradiol-17 $\beta$ or PGE-2 remained fully functional until Day 19 , whereas CL implanted with oestradiol$17 \beta \pm$ PGF- $2 \alpha$ and PGE-2 + PGF-2 $\alpha$ exhibited lower $(P<0.05)$ weight and progesterone concentrations; $C L$ implanted with PGE-2 + PGF-2 $\alpha$ were heavier $(P<0.05)$ and tended $(P<0 \cdot 10)$ to have greater progesterone concentrations than CL implanted with oestradiol-17 $\beta+$ PGF- $2 \alpha$. In Exp. 3, a dose-dependent $(P<0.05)$ effect of PGE-2 on preventing regression induced by PGF- $2 \alpha$ was observed on Day 19. These data demonstrate a direct effect of PGE-2, but not of oestradiol-17 $\beta$ in protecting the CL against luteolysis induced by PGF- $2 \alpha$.
\end{abstract}

Keywords: oestradiol-17ß; prostaglandin E-2; prostaglandin F-2 $\alpha$; intraluteal implants; corpus luteum; pig

\section{Introduction}

Evidence for a direct effect of an embryonic luteotrophin is provided by the observed high incidence of unilateral maintenance (Anderson, 1966; Niswender et al., 1970; Christenson \& Day, 1971) and high progesterone concentrations (Ford \& Christenson, 1979) of corpora lutea (CL) adjacent to the gravid uterine horn in unilaterally pregnant pigs. Additional direct evidence of embryonic factors preventing the luteolytic effect of prostaglandin F-2 $\alpha$ (PGF-2 $\alpha$ ) in pigs at the level of the CL is provided by Ball \& Day (1982). In their study, luteal implants containing embryonic extracts and PGF-2 $\alpha$ were placed in individual CL on Days 30-35 of pregnancy. Implants with both embryonic extract and PGF- $2 \alpha$ were heavier and contained more progesterone than those containing PGF- $2 \alpha$ alone, which suggests that embryonic factors directly prevented the luteolytic response. Furthermore, Ball \& Day (1982) observed that charcoal extraction of embryonic homogenates removed the luteotrophic factor(s), which indicated a compound of low $M_{\mathrm{r}}$, such as a prostaglandin or steroid.

Pig embryos produce both oestradiol-17 (Perry et al., 1976) and prostaglandin E-2 (PGE-2; Geisert et al., 1982a) at the time of maternal recognition of pregnancy (Days 11-13) and both compounds are known to be luteotrophic in this species (Geisert et al., 1987; Akinlosotu et al., 1986). The mechanism or mechanisms whereby these compounds extend luteal function are unclear. It is generally believed that the luteotrophic effect of oestrogen in pigs is indirect, resulting

*Reprint requests. 
from a reduced uterine release of PGF-2 $\alpha$ into the peripheral circulation (Bazer et al., 1986; Conley \& Ford, 1989; Conley et al., 1989). Prostaglandin E-2 has been shown to antagonize directly the luteolytic effects of exogenously administered PGF- $2 \alpha$ in ewes when both compounds are administered simultaneously into the ovarian artery (Henderson et al., 1977) or into the mesovarium around the ovarian vascular pedicle (Reynolds et al., 1981). Similar studies in pigs have not been reported.

The studies reported here evaluated directly the effects of the known porcine conceptus secretory products oestradiol-17 $\beta$ and PGE-2 in preventing the luteolytic effect of PGF-2 $\alpha$ on individual pig CL.

\section{Materials and Methods}

Animals. Yorkshire gilts $(n=19) 6-8$ months old and weighing $120-150 \mathrm{~kg}$, which had exhibited two oestrous cycles of normal duration (19-21 days), were assigned to surgery on Day 11 (Day $0=$ first day of oestrus). Anaesthesia was induced with Surital (Park-Davis, Morris Plains, NJ, USA) and maintained with Halothane (Halocarbon Laboratories Inc., Hackensack, NJ) and oxygen (Magness \& Ford, 1982).

Ovaries were exposed by midventral laparotomy and gilts were assigned to one of 3 experiments.

Experiment 1. Number of corpora lutea was determined on both ovaries of each gilt $(n=4)$ and an ovary with $>8$ $\mathrm{CL}$ was selected to receive intraluteal silastic implants (treated ovary). Pairs of CL on the treated ovary were selected at random to receive implants containing (i) $10 \mathrm{mg}$ oestradiol-17 $\beta$, (ii) $100 \mu \mathrm{g}$ PGF-2 $\alpha$, (iii) $10 \mathrm{mg}$ oestradiol-17 $\beta+$ $100 \mu \mathrm{g}$ PGF-2 $\alpha$ or (iv) vehicle (silastic only). Pairs of implanted CL were then marked with different numbers of silk ligatures, depending upon treatment group. Ligatures were placed in the ovarian stroma between members of the pair. On the treated ovary, the CL in addition to the 8 implanted CL $(1-3)$, as well as all CL on the other ovary, served as unimplanted controls.

Experiment 2. Two pairs of CL on each ovary of five gilts were used. Each pair was randomly assigned to receive

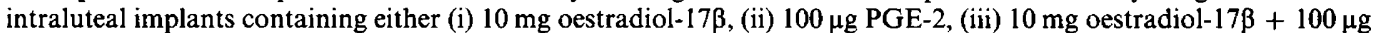
PGF-2 $\alpha$ or (iv) $100 \mu \mathrm{g}$ PGE-2 $+100 \mu \mathrm{g}$ PGF- $2 \alpha$. An additional pair of CL, on the ovary with the greatest number of $\mathrm{CL}$ within each gilt, was selected to receive vehicle implants. All CL on each ovary not receiving implants served as unimplanted controls.

Experiment 3. The number of CL on each ovary of five gilts was determined and three pairs of CL on an ovary in each gilt with $>8 \mathrm{CL}$ were selected to receive implants containing (i) $100 \mu \mathrm{g}$ PGE-2 $+100 \mu \mathrm{g}$ PGF-2 $\alpha$, (ii) $200 \mu \mathrm{g}$ PGE-2 $+100 \mu \mathrm{g}$ PGF-2 $\alpha$ or (iii) $400 \mu \mathrm{g}$ PGE-2 $+100 \mu \mathrm{g}$ PGF- $2 \alpha$. Four CL on the opposite ovary were selected to receive $10 \mathrm{mg}$ oestradiol-17 $\beta+100 \mu \mathrm{g}$ PGF-2 $\alpha$. All unimplanted $\mathrm{CL}$ on both ovaries served as controls.

After pairs of CL were marked for later identification, ovaries were returned to the body cavity, and gilts were allowed to recover. On Day 19, all gilts (Exps 1 to 3) were relaparotomized and their ovaries surgically removed. Corpora lutea on both ovaries of each gilt were immediately identified as to treatment group and excised from the ovaries. The weights of all CL were then recorded. Weights of implanted CL were recorded before and after the removal of the implant. Implant weights in these three studies were similar, averaging $50 \pm 5 \mathrm{mg}$. All CL were individually homogenized and frozen at $-20^{\circ} \mathrm{C}$ until determination of progesterone concentration by a specific radioimmunoassay.

Control animals. To confirm an effect of oestradiol-17ß on bilateral maintenance of CL at the dose used in these studies, two gilts subjected to sham surgery on Day 11 , and three unoperated control gilts were slaughtered on Day 19. Corpora lutea were collected, weighed, and frozen as for treated gilts.

Implant preparation. Silastic compound was prepared by mixing equal quantities of Medical Grade Elastomer \#382 and Medical Fluid $\# 360$ (Dow Corning Corporation, Midland, MI) with catalyst (stannous octoate: Dow Corning Corporation, Midland, MI) in a sterile tube containing hormone, which resulted in curing of the compound within $3 \mathrm{~min}$. During this period, the compound remained fluid enough to pass through an 18-gauge needle, enabling the injection of $50 \mu \mathrm{l}$ of silastic compound into individual $\mathrm{CL}$, and the in-situ formation of solid intraluteal implants. Implants containing oestradiol-17 $\beta$, PGE-2, PGF- $2 \alpha$ or combinations were prepared by combining 10 times the amount of crystalline hormone(s) required for each implant with silastic compound prior to addition of Medical Fluid and catalyst to a final volume of $0.5 \mathrm{ml}$.

Progesterone radioimmunoassay. Concentrations of progesterone in porcine luteal tissue were determined as described by Ford \& Christenson (1979) and using the same fully characterized antisera (\$GDN337). Sensitivity of the assay was defined as the amount of steroid that yielded $95 \%$ of the c.p.m. in the buffer control tubes, which averaged $50 \mathrm{pg}$. Intra- and interassay coefficients of variation for a luteal tissue pool $(27478 \pm 1126 \mathrm{ng} / \mathrm{mg} ; n=6)$ were $9 \cdot 1$ and $10.0 \%$, respectively. 
Statistical analysis. Arithmetic means of $\mathrm{CL}$ weight and progesterone content and concentration were calculated for each set of implanted CL within a gilt, as well as all unimplanted CL on each ovary. These means were used to calculate treatment group means and for statistical comparisons. The effects of treatment on luteal weight and progesterone content and concentration were tested by analysis of variance for a randomized block in which animals served as blocks. Upon observation of a significant treatment effect $(P<0.05)$, treatments within a study were compared using Duncan's multiple range test.

\section{Results}

\section{Experiment 1}

Uninjected control CL were similar in weight and progesterone content and concentration on Day 19, regardless of location (treated or control ovary); thus, values were pooled within a gilt (Fig. 1). On the treated ovary, CL containing silastic implants releasing oestradiol-17 $\beta$ were similar in weight and progesterone content and concentration to vehicle-implanted and unimplanted, control CL. Pairs of CL receiving implants containing PGF- $2 \alpha$ with or without oestradiol-17 $\beta$ appeared to be regressing, as shown by their blanched appearance and their significantly $(P<0.01)$ lower weights and progesterone content and concentrations than those of the other CL groups. These CL implanted with PGF-2 $\alpha$ were similar in weight and in progesterone content and concentration to the CL of Day-19 surgical and nonsurgical control gilts, whose values were similar and averaged $112 \pm 15 \mathrm{mg}, 695 \pm 172 \mathrm{ng}$, and $3 \cdot 1 \pm 0 \cdot 2 \mathrm{ng} / \mathrm{mg}$, respectively.

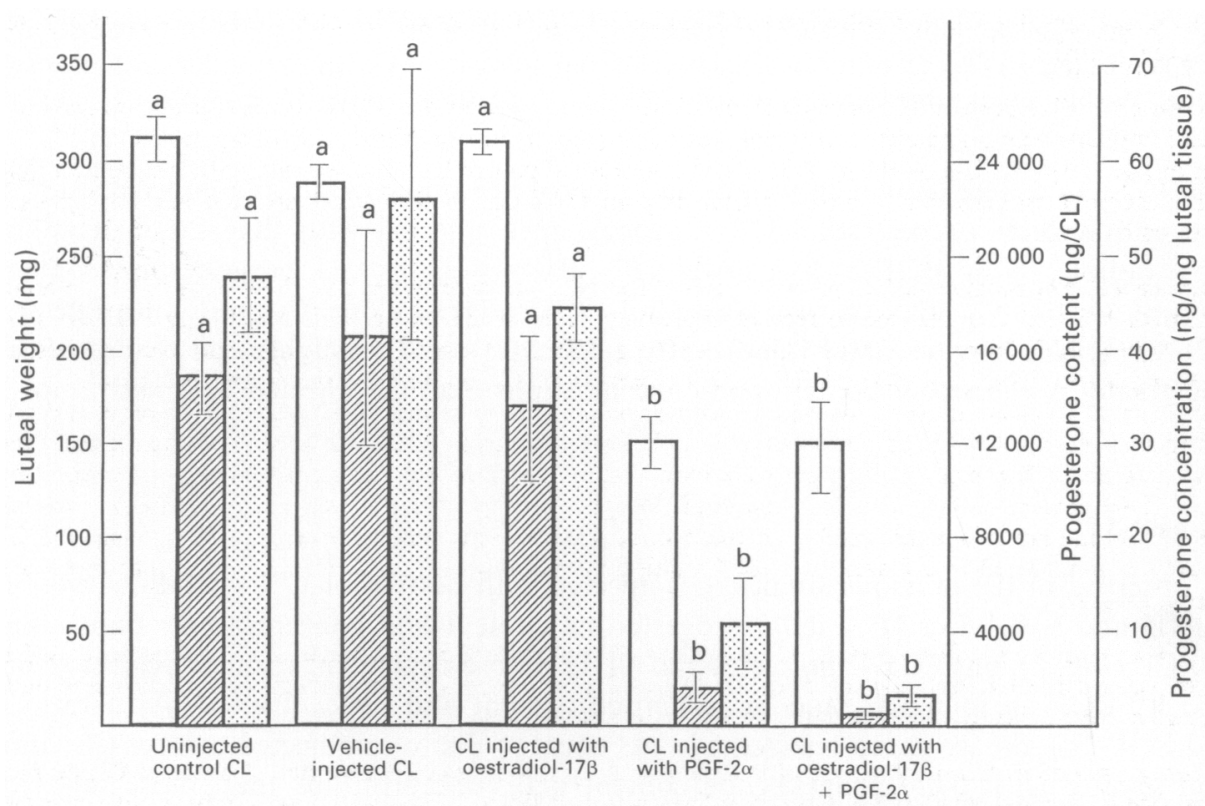

Fig. 1. Average weights $(\square)$ and progesterone content $(\square)$ and concentrations ( $(0)$ of pairs of corpora lutea (CL) collected on Day 19 of the oestrous cycle from gilts $(n=4)$ in Exp. 1. Values are means \pm s.e.m. Within a measurement, means with different superscripts differ $(P<0.01)$.

\section{Experiment 2}

Changes in progesterone content of $\mathrm{CL}$ followed those of progesterone concentration. As observed in Exp. 1, uninjected, vehicle-injected and oestradiol-17 $\beta$-injected CL were similar in weight and in progesterone content and concentration (Fig. 2). Corpora lutea injected 


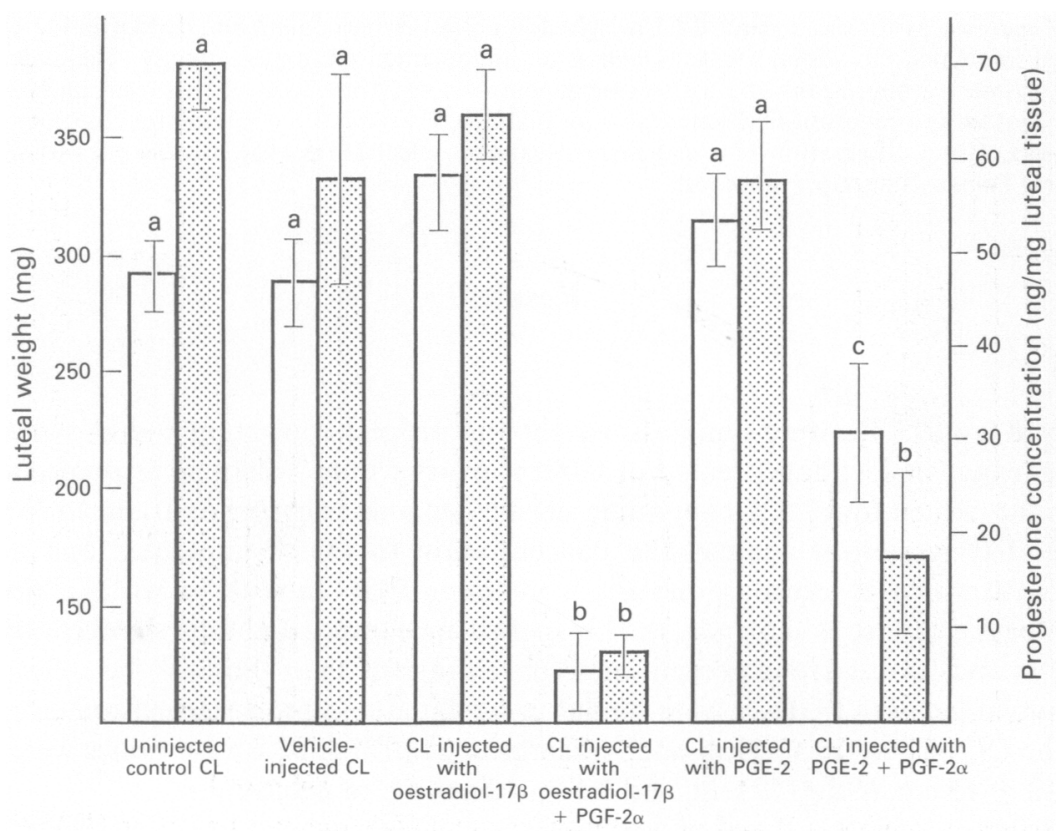

Fig. 2. Average weights ( $\square$ ) and progesterone concentrations (圈) of pairs of corpora lutea (CL) collected on Day 19 of the oestrous cycle from gilts $(n=5)$ in Exp. 2. Values are means \pm s.e.m. Within a measurement, means with different superscripts differ $(P<0.05)$.

with PGE-2 alone were similar in weight and in progesterone content and concentration to CL injected with vehicle or oestradiol-17 $\beta$. Corpora lutea injected with PGF- $2 \alpha$, in combination with oestradiol-17 $\beta$ or PGE-2, had lower $(P<0.05)$ weights and progesterone content and concentrations than $C L$ injected with oestradiol-17 $\beta$ or PGE-2 alone. Corpora lutea injected with PGE-2 + PGF-2 $\alpha$, however, had significantly greater $(P<0 \cdot 05)$ weights and tended $(P<0 \cdot 10)$ to have greater progesterone content and concentrations than $C L$ injected with oestradiol-17 $\beta+$ PGF-2 $\alpha$.

\section{Experiment 3}

As observed in the previous studies, CL injected with oestradiol-17 $\beta+$ PGF- $2 \alpha$ were lighter $(P<0.01)$ and had lower $(P<0.01)$ progesterone content and concentrations than uninjected control CL (Fig. 3); but PGE-2 protected the CL in a dose-dependent manner against reductions induced by PGF- $2 \alpha$ in weight and progesterone content and concentration. At a ratio of $4: 1$ (PGE-2:PGF-2 $\alpha$ ), the weight of injected CL was equal to that of uninjected control CL; and these CL had greater $(P<0.05)$ progesterone content and concentrations than those injected with oestradiol-17 $\beta+$ PGF- $2 \alpha$.

\section{Discussion}

These studies are the first to investigate the specific effects of oestradiol-17 $\beta$ and PGE-2 in protecting individual pig CL from the luteolytic effects of PGF-2 $\alpha$. Because treatments were administered to individual CL, we eliminated any indirect effect(s) of oestradiol-17 $\beta$ or PGE-2 at either the uterus or the hypothalamic-pituitary axis. These studies used intraluteal administration of oestradiol-17ß on Day 11, to maintain all CL bilaterally until Day 19 of the oestrous cycle, as 


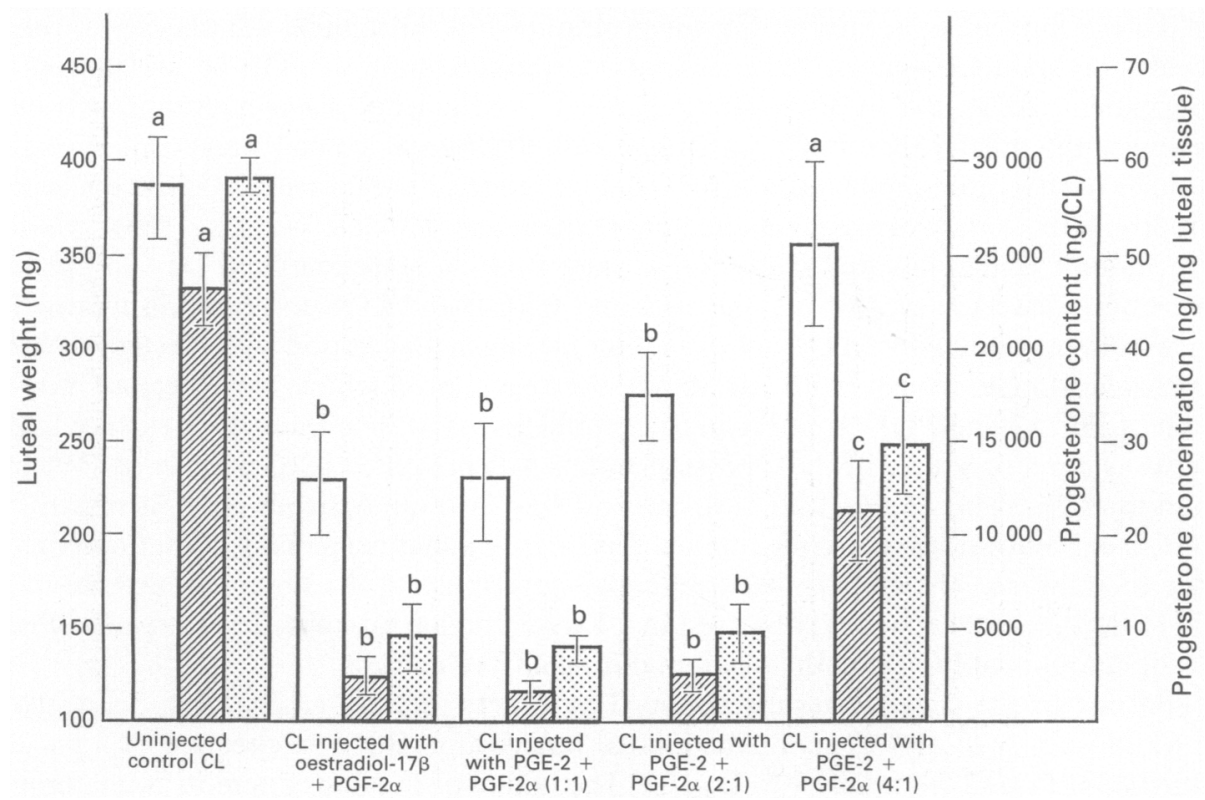

Fig. 3. Average weights $(\square)$ and progesterone content $(\square)$ and concentration (圈) of pairs of corpora lutea (CL) collected on Day 19 of the oestrous cycle from gilts $(n=5)$ in Exp. 3. Values are means \pm s.e.m. Within a measurement, means with different superscripts differ $(P<0.05)$.

reported by Conley \& Ford (1989). The studies reported here used a dose of $40 \mathrm{mg}(10 \mathrm{mg} / \mathrm{CL}$ in 4 $\mathrm{CL})$ per gilt which is approximately four times the dose of oestradiol-17 $3(1.5 \mathrm{mg} / \mathrm{CL}$ in $6.5 \mathrm{CL})$ previously shown (Conley et al., 1989) to suppress PGF-2 $\alpha$ release from the uterus until Day 19 in gilts.

These studies demonstrate that, even at a ratio of $100: 1$, oestradiol-17 $\beta$ was unable to protect a $\mathrm{CL}$ against the simultaneous intraluteal administration of PGF-2 $\alpha$. These data support the conclusions of Bazer et al. (1986), who suggested that the predominant effect of oestradiol-17 $\beta$ in extending luteal function in gilts is through its effect on inhibiting uterine release of PGF- $2 \alpha$. In support of this concept, Conley \& Ford (1989) reported that intraluteal oestradiol-17 $\beta$ could directly stimulate the growth of an individual $\mathbf{C L}$, but only if the release rate of oestradiol-17 $\beta$ was high enough to maintain all CL bilaterally. In contrast, Kraeling et al. (1975) reported that oestrogen prevented CL regression induced by PGF-2 $\alpha$ in hysterectomized gilts. Unfortunately, no details were provided by these researchers on how luteal maintenance was assessed.

Significant experimental evidence suggests that pig embryos may exert a direct luteotrophic effect. This evidence includes the high incidence of unilateral maintenance (Christenson \& Day, 1971) and high progesterone concentrations (Ford \& Christenson, 1979) of CL adjacent to the gravid uterine horn in unilaterally pregnant pigs. In addition, Ford et al. (1982) observed transient increases in luteal blood flow in gilts at the time of maternal recognition of pregnancy. Ball \& Day (1982) used intraluteal implants containing porcine embryonic extracts to maintain the function of individual CL on an ovary. In contrast to the results obtained by Conley \& Ford (1989) with oestradiol-17ß, no systemic luteotrophic effect seemed necessary to elicit this response, suggesting that embryonic extract prevented the luteolytic effects of the uterus at the level of the CL. The active principle or principles were heat stable and charcoal extractable, indicating that they were of a low $M_{\mathrm{r}}$ and thus possibly a steroid or prostaglandin. The data obtained in this study suggest that, if involved, oestradiol-17 $\beta$ is not the only antiluteolytic factor produced by pig embryos. 
Unlike the intraluteal administration of oestradiol-17 $\beta$, intraluteal administration of PGE-2 protected individual CL against the concomitant administration of PGF-2 $\alpha$ and this effect was dose dependent. At PGE-2:PGF-2 $\alpha$ ratios of 4:1, CL weight and P4 content and concentration were significantly greater than in $\mathrm{CL}$ implanted with PGF-2 $\alpha$ alone and weights of implanted $\mathrm{CL}$ were similar to that of unimplanted control CL. Few reports have measured PGE-2 concentrations in the reproductive tissues of pregnant and nonpregnant pigs. Patek \& Watson (1983) demonstrated that arachidonic acid stimulated more PGE-2 than PGF- $2 \alpha$ secretion from Day-20 pregnant pig endometrium. Geisert et al. (1982a) reported that PGE-2 and PGF increased in uterine luminal flushings from pregnant gilts on Day 11 to 14 after mating in association with blastocyst elongation and occurred simultaneously with blastocyst oestrogen production; this increase may reflect secretion of PGE-2 and PGF from the uterine epithelium and/or blastocyst. Evidence suggesting the uterus as a major source of these prostaglandins was presented by Geisert et al. (1982b), who observed that treatment of gilts with oestrogen on Day 11 of an oestrous cycle increased PGF- $2 \alpha$ and PGE-2 concentrations in uterine luminal flushings in a manner similar to that observed in the presence of embryos. The embryo itself may also contribute to the observed increase in uterine luminal PGE-2; Paria et al. (1987) observed that Day-5 porcine blastocysts are capable of releasing significant amounts of PGE-2 in the medium during $48 \mathrm{~h}$ of culture.

In contrast to the negative results obtained by others (Sander et al., 1982; Schneider et al., 1983), Akinlosotu et al. (1986) maintained luteal function in gilts by a constant or a pulse (every $4 \mathrm{~h}$ )-infusion of PGE-2 from Day 7 to Day 23. The failure of previous attempts to maintain luteal function with PGE-2 may be due to the delayed start of the infusion period or to the less rigorous infusion regime over those days. Further, because intra-uterine infusion of PGE-2 on Days 12, 15 or 18 of the oestrous cycle is known to stimulate PGF-2 $\alpha$ release by the pig uterus (Okrasa et al., 1985), PGF-2 $\alpha$ may have overcome the luteotrophic effect of PGE-2.

These data suggest that the major antiluteolytic effect of oestradiol-17 $\beta$ in oestrogen-induced pseudopregnant gilts is to decrease uterine release of PGF- $2 \alpha$ into the peripheral circulation, rather than a direct protective effect at the level of the CL. When uterine release of PGF-2 $\alpha$ is reduced by oestradiol-17 $\beta$, PGE-2 protects individual CL from the luteolytic effects of exogenously administered PGF-2 $\alpha$. Since both oestradiol-17 $\beta$ and PGE-2 are produced synchronously with PGF- $2 \alpha$ during early pregnancy, an independent role for each compound in protecting the CL from luteolysis induced by PGF-2 $\alpha$ can be envisaged.

We thank T. Breon, C. Hertz and M. Kaminski for their technical expertise and D. Johnston for typing this manuscript.

Journal Paper J-14274 of the Iowa Agriculture and Home Economics Experiment Station, Ames: Projects 2443 and 2444.

\section{References}

Akinlosotu, B.A., Diehl, J.R. \& Gimenez, T. (1986) Sparing effects of intrauterine treatment with $\mathrm{PGE}_{2}$ on luteal function in cycling gilts. Prostaglandins 32, 291-297.

Anderson, L.L. (1966) Pituitary-ovarian-uterine relationships in pigs. J. Reprod. Fert., Suppl. 1, 21-37.

Ball, G.D. \& Day, B.N. (1982) Local effects of PGF PG $_{2}$ and embryonic extracts on luteal function in swine. J. Anim. Sci. 54, 150-154.

Bazer, F.W., Vallet, J.L., Roberts, R.M., Sharp, D.C. \& Thatcher, W.M. (1986) Role of conceptus secretory products in establishment of pregnancy. J. Reprod. Fert. 76, 841-850.

Christenson, R.K. \& Day, B.N. (1971) Maintenance of unilateral pregnancy in the pig with induced corpora lutea. J. Anim. Sci. 32, 282-286.
Conley, A.J. \& Ford, S.P. (1989) Direct luteotrophic effect of oestradiol-17 $\beta$ on pig corpora lutea. J. Reprod. Fert. 87, 125-131.

Conley, A.J., Pusateri, A.E., Van Orden, D.E. \& Ford, S.P. (1989) Effect of intraluteal estradiol-17\% implants on weight and progesterone secretion of porcine corpora lutea. Ann. Reprod. Sci. 20, 221-230.

Ford, S.P. \& Christenson, R.K. (1979) Blood flow to the uteri of sows during the estrous cycle and early pregnancy: local effect of the conceptus on the uterine blood supply. Biol. Reprod. 21, 617-624.

Ford, S.P., Reynolds, L.R. \& Magness, R.R. (1982) Blood flow to the uterine and ovarian vascular beds of gilts during the estrous cycle or early pregnancy, Biol. Reprod. 27, 878-885. 
Geisert, R.D., Renegar, R.H., Thatcher, W.W., Roberts, R.M. \& Bazer, F. (1982a) Establishment of pregnancy in the pig. I. Interrelationships between preimplantation development of the pig blastocyst and uterine endometrial secretions. Biol. Reprod. 27, 925939.

Geisert, R.D., Renegar, R.H., Thatcher, W.W., Roberts, R.M. \& Bazer, F.W. (1982b) Establishment of pregnancy in the pig. III. Endometrial secretion response to estradiol valerate administered on d 11 of the estrous cycle. Biol. Reprod. 27, 957-965.

Geisert, R.D., Zavy, M.T., Wettemann, R.P. \& Biggers, B.G. (1987) Length of pseudopregnancy and pattern of uterine protein release as influenced by time and duration of oestrogen administration in the pig. $J$. Reprod. Fert. 79, 163-172.

Henderson, K.M., Scaramuzzi, R.J. \& Baird, D.T. (1977) Simultaneous infusion of prostaglandins $E_{2}$ antagonizes the luteolytic action of prostaglandin $F_{2} \alpha$ in vivo. Endocrinology 72, 379-386.

Kraeling, R.R., Rampacek, B.G. \& Ball, G.D. (1975) Estradiol inhibition of $\mathrm{PGF}_{2} \alpha$ luteolysis in the pig. J. Anim. Sci. 41 (Suppl. 1), 363, abstr.

Magness, R.R. \& Ford, S.P. (1982) Steroid concentrations in uterine lymph and uterine arterial plasma of gilts during the estrous cycle and early pregnancy. Biol. Reprod. 27, 871-877.

Niswender, G.D., Dziuk, P.J., Kaltenbach, C.C. \& Norton, H.W. (1970) Local effect of embryos and the uterus on corpora lutea in gilts. J. Anim. Sci. 30, 225-228.
Okrasa, S.O., Tilton, J.E. \& Weigel, R.M. (1985) Uteroovarian venous concentrations of $\mathrm{PGE}_{2}$ and $\mathrm{PGF}_{2} \alpha$ following $\mathrm{PGE}_{2}$ intrauterine infusions. Prostaglandins 30, 851-856.

Paria, B.C., Davis, D.L. \& Rosenkrans, C.F., Jr (1987) Prostaglandin production by zona enclosed pig blastocysts. Biol. Reprod. 36 (Suppl. 1), 38, abstr.

Patek, C.E. \& Watson, J. (1983) Factors affecting steroid and prostaglandin secretion by reproductive tissues of cycling and pregnant sows in vitro. Biochim. Biophys. Acta 755, 17-25.

Perry, J.S., Heap, R.B., Burton, R.D. \& Gadsby, J.E. (1976) Endocrinology of the blastocyst and its role in the establishment of pregnancy. J. Reprod. Fert. 28, 85-104.

Reynolds, L.P., Stigler, J., Hoyer, G.L., Magness, R.R., Huie, J.M., Huecksteadt, T.P., Whysong, G.L., Behrman, H.R. \& Weems, C.W. (1981) Effect of $\mathrm{PGE}_{1}$ or $\mathrm{PGE}_{2}$ on $\mathrm{PGF}_{2} \alpha$-induced luteolysis in nonbred ewes. Prostaglandins 21, 957-972.

Sander, H., Bruhn, R., Elger, N. \& Ellendorf, F. (1982) Prostaglandin E (sulproston) is neither luteolytic nor luteotrophic during the estrous cycle. Prostaglandins 24, 691-700.

Schneider, T.M., Tilton, J.E., Okrasa, S., Mah, J., Weigl, R. \& Williams, G.L. (1983) The effect of intrauterine infusions of $\mathrm{PGE}_{2}$ on luteal function in nonpregnant gilts. Theriogenology 20, 509-520.

Received 9 November 1990 